\title{
Experiences, attitudes and barriers towards research amongst junior faculty of Pakistani medical universities Saniya Sabzwari ${ }^{1}$, Samreen Kauser ${ }^{1}$ and Ali Khan Khuwaja*2
}

Address: ${ }^{1}$ Department of Family Medicine, Aga Khan University, Karachi, Pakistan and ${ }^{2}$ Department of Community Health Sciences, Aga Khan University, Karachi, Pakistan

Email: Saniya Sabzwari - saniya.sabzwari@aku.edu; Samreen Kauser - samreen.kauser@aku.edu; Ali Khan Khuwaja* - ali.khuwaja@aku.edu

* Corresponding author

Published: 16 November 2009

BMC Medical Education 2009, 9:68

This article is available from: http://www.biomedcentral.com/I472-6920/9/68

(c) 2009 Sabzwari et al; licensee BioMed Central Ltd.

This is an Open Access article distributed under the terms of the Creative Commons Attribution License (http://creativecommons.org/licenses/by/2.0), which permits unrestricted use, distribution, and reproduction in any medium, provided the original work is properly cited.
Received: 13 January 2009

Accepted: 16 November 2009

\begin{abstract}
Background: The developing world has had limited quality research and in Pakistan, research is still in its infancy. We conducted a study to assess the proportion of junior faculty involved in research to highlight their attitude towards research, and identify the factors associated with their research involvement.
\end{abstract}

Methods: A cross-sectional study was conducted in four medical universities/teaching hospitals in Pakistan, representing private and public sectors. A pre-tested, self-administered questionnaire was used to collect information from 176 junior faculty members of studied universities/hospitals. Logistic regression analysis was used to identify factors related to attitudes and barriers in research among those currently involved in research with those who were not.

Results: Overall, $41.5 \%$ of study subjects were currently involved in research. A highly significant factor associated with current research involvement was research training during the post-graduate period $(p<0.00 \mathrm{I})$. Other factors associated with current involvement in research were male gender, working in the public sector and previous involvement in research. Overall, a large majority (85.2\%) of doctors considered research helpful in their profession and had a positive attitude towards research; nevertheless this positive attitude was more frequently reported by doctors who were currently involved in research compared to those who were not $(\mathrm{OR}=4.69 ; 95 \% \mathrm{Cl}=$ I.54-14.26). Similarly, a large proportion (83.5\%) of doctors considered research difficult to conduct; higher by doctors who were not presently involved in research $(O R=2.74 ; 95 \% \mathrm{Cl}=$ I.20-6.22)

Conclusion: Less than half of the study participants were currently involved in research. Research output may improve if identified barriers are rectified. Further studies are recommended in this area.

\section{Background}

Health research is essential in improving health care and plays a central role in the field of medicine. Advances in disease surveillance, diagnosis, treatment and prevention all rely heavily on quality research. In addition research influences health care policy [1]. Critical thinking skills of individuals are also greatly enhanced as a result of their involvement in research. Clinicians incorporate informa- 
tion from clinical research trials [2] into their practices, which improves patient management and disease outcome. Globalization of diseases and the increasing need of incorporation of evidence based medicine into practice have made quality demographic and clinical research even more imperative.

For a long time most of the developing world relied on research findings, interpretation and application from the western world. This did not always provide the solution to the problems of developing countries. Slow advances however, have been made in medical research in developing countries [3] and more funding, material and logistic support has been provided for conducting research. Nevertheless, the quality of research is affected by lack of expertise in research skills [4]. Problems are also seen in sharing and dissemination of results locally [5] and in incorporation of research findings in policy making [4]; either because a lack of understanding of research findings or its clinical implications by the health policy makers.

Literature shows that clinicians' interest and involvement in research has declined in recent years [6,7]. Several studies have looked at attitudes and interest in research among doctors working in various specialties and subspecialties. In the primary care field, most studies found time, financial constraints [7], busy clinical practices [8] and lack of interest [9] as major deterrents to clinicians' involvement in research. Other similar studies identified financial incentives and infrastructure support as key factors in promoting research [10]. Age and gender differences in research interest were also seen with younger physicians showing more inclination towards research [11] and a comparatively smaller involvement of female physicians [7]. Inadequate mentorship and lack of time have been other major barriers in research $[12,13]$. Bland and Ruffin [14] and Brocato and Mavis [15] identified accessible resources, appropriate rewards, time allocation, promotion and tenure as stimulators for research and scholarly productivity.

Pakistan is teeming with a multitude of medical, environmental and psychosocial issues which are just waiting to be explored. However, research here like most developing countries is in its infancy. This country faces obstacles in medical research which are similar to other developing countries. With a few exceptions, there is little quality research in Pakistan and a large majority of work is compromised due to flawed methodology and poor research training and background of researchers [5].

Some efforts are being made to improve training in research both at undergraduate and post graduate level yet research output still remains low [3]. Most of the research being produced is through required papers generated by postgraduate trainees [16]; which is a mandatory require- ment for their training. It is therefore important to understand and highlight the attitudes and problems of health care providers in conducting quality research. This may help identify barriers and further encourage research by young professionals so that future research is more in number, better in quality and greater in impact. This study aimed to assess the proportion of junior faculty members of Pakistan's teaching medical institutes who are currently involved in research and to identify the factors associated with their involvement in research. In addition, we also assessed the attitudes and barriers towards research among these participants.

\section{Methods}

A cross-sectional study was conducted in four medical universities/teaching hospitals in Pakistan: two each from the public and private sector. Self-administered and anonymous questionnaire was distributed to 220 eligible consenting study participants. The questionnaire was collected back after completion within one week of distribution. For those who had not returned the completed questionnaire by the due date, a reminder was given and another week was offered for completion of the questionnaire. Full confidentiality of the data collected was ensured to all the study participants and their representing universities/hospitals. They were also assured that the results of this study would not be presented either at an individual study participant or university/hospital level. Even though, no harm was expected to occur to any of the participating faculty and/or university, the study questionnaire was reviewed and approved by the Research Committee of the department of Family Medicine, Aga Khan University, Karachi. All data collection was done by medical graduates who received prior training for this task.

A structured questionnaire was designed incorporating important barriers and attitudes in research that were identified through an extensive literature search of the Pub Med database. After consensus of all study investigators, we also included some questions, which were particularly important to our local scenario. Questions about past research involvement and experiences were also included. The time required to complete the questionnaire was about 10 to 12 minutes. In all, 18 questions were included in the study questionnaire. The first five were about study participants' back ground information; the next seven about research training, publications, projects and grant obtained; followed by two questions each about research attitudes, barriers and future plans. The format of all the responses was in categorical design (yes/no and by choosing appropriate responses among already given options). Face and content validity of the questionnaire was obtained through a review process with experts in the field. After incorporating the identified inconsistencies and inaccuracies, the questionnaire was 
pre-tested on a group of family medicine residents to identify any problems relating to question design, flow and interpretation. This was also done to ensure that the questionnaire was in concordance with the study objectives. Suggestions given were incorporated accordingly.

This study included only those faculty members who were working as Junior faculty (Fellows, Instructors, Senior Instructors and Assistant Professors) at participating universities/hospitals. Senior faculty at associate professor and above were not included and interviewed in this study, as in our setting prior research done during the course of their careers and current seniority made their knowledge, experiences and needs different from junior faculty. We also excluded those faculty members who have reviewed the study questionnaire and protocol previously during its development and finalization phase. Faculty members from the departments of community health sciences and basic health sciences were also not included in this study, as their training and focus in research was more structured and comprehensive compared to other departments making them more productive in research.

Data was analyzed using Statistical Package for Social Sciences (SPSS) version 16. The proportion of junior faculty members who were currently involved in research was calculated. Chi-square test was used to assess the association between the outcome variable (current involvement in research) and the variables related to study participants' work and training. The differences in proportion of attitude and barriers towards research were calculated between those who were currently involved in research versus those who were not involved by logistic regression analysis with 95\% confidence intervals of odds ratios.

\section{Results}

In all, 220 eligible study participants were approached; out of which 191 responded (response rate was 87\%). However, in final analysis we only included $176 \mathrm{com}-$ pleted questionnaires. Majority of the junior faculty members working in medical universities of Pakistan were men 35 years and older. Majority (56.2\%) of the study subjects were working in medicine and allied specialties and $67.6 \%$ in private sector universities. Almost equal percentages of faculty were working at Level I (Fellows, Instructors and Lecturers) and Level II (Senior Instructors and Assistant Professors). A very small proportion (6.8\%) of study participants received research training during their undergraduate years, while majority $(63.1 \%)$ of the subjects had obtained research training during postgraduate studies. A large number (59.7\%) of study participants had prior research involvement and about half of them had at least one research publication and presentation to their credit (table 1).
In all, $41.5 \%$ of study participants were currently involved in research; a significantly higher proportion of men compared to women (men: $50.0 \%$ and women: $30.8 \%$; p = 0.01 ) and those working in public sector versus private sector universities (public: $52.6 \%$ and private: $36.1 \%$; $\mathrm{p}=$ 0.04 ). Faculty working in medicine and allied department(s) were currently involved in research at a higher proportion compared to their counterparts in surgery and allied department(s); however the difference was not statistically significant. The most significant factor associated with current involvement in research was research training during postgraduate education $(p<0.001)$. Those who had research training during their postgraduate years were involved in current research at a significantly higher proportion 55.0\% compared to those who had not, $18.5 \%$. Similarly those who were previously involved in research and had research publications and presentations were currently involved in research at significantly higher proportions (table 1).

Attitudes and barriers towards research and differences amongst those currently involved in research versus those who were not, are given in table 2. Overall, a preponderance of study subjects reported a positive attitude toward research particularly those who were currently involved in research. A large majority (85.2\%) of study participants agreed that research was helpful and this proportion was significantly higher among those currently participating in research $(94.5 \%)$ as compared to those who were not participating in research $(78.6 \%)(\mathrm{OR}=4.69 ; 95 \% \mathrm{CI}=$ $1.54-14.26 ; \mathrm{p}=0.003)$. Amongst doctors who reported that research as helpful; a higher proportion of those who were presently involved in research reported that research promote critical thinking as compared to those who were not involved in research $(\mathrm{AOR}=2.48 ; 95 \% 1.22-5.05)$. Similarly, about half of the study subjects reported that research improve patient care and this positive attitude was higher among those who were involved in current research $(\mathrm{AOR}=2.11 ; 1.05-4.25)$ (Table 2$)$.

Over $83 \%$ of study subjects admitted that research was difficult to conduct and this is higher among those who were not involved in research currently $(89.3 \%)$ as compared to those who were involved $(75.3 \%)(\mathrm{OR}=2.74 ; 95 \% \mathrm{CI}$ $=1.20-6.22 ; \mathrm{p}=0.01)$. Lack of training as barrier towards research was reported by $68.0 \%$ of study subjects who were not involved in current research compared to $52.1 \%$ by those who were currently involved in research $(\mathrm{OR}=$ $1.95 ; 95 \% \mathrm{CI}=1.05-3.62)$. The other barriers were almost equally identified by both the groups. (Table 2).

\section{Discussion}

To the best of our knowledge, this study is the first attempt in Pakistan that looked at characteristics of physicians and challenges in research faced by early to mid career level 
Table I: Proportion and factors associated with present involvement in research among junior faculty members of teaching hospitals in Pakistan

\begin{tabular}{|c|c|c|c|c|}
\hline Factors & $\begin{array}{l}\text { Total faculty } \\
(n=176) \\
\text { Percentages }\end{array}$ & $\begin{array}{l}\text { Percent presently involved in } \\
\text { research } \\
(n=73)\end{array}$ & $\begin{array}{l}\text { Percent presently not involved in } \\
\text { research } \\
(n=103)\end{array}$ & p-value \\
\hline Sex & & & & 0.01 \\
\hline - Women & 44.3 & 32.9 & 52.4 & \\
\hline - Men & 55.7 & 67.1 & 47.6 & \\
\hline Age in years & & & & NS \\
\hline$-<35$ & 46.6 & 49.3 & 44.7 & \\
\hline$-\geq 35$ & 53.4 & 50.7 & 55.3 & \\
\hline Department & & & & NS \\
\hline - Surgery and allied & 43.8 & 37.0 & 48.5 & \\
\hline - Medicine and allied & 56.2 & 63.0 & 51.5 & \\
\hline Type of university & & & & 0.04 \\
\hline - Private sector & 67.6 & 58.9 & 73.8 & \\
\hline - Public sector & 32.4 & 41.2 & 26.2 & \\
\hline Designation & & & & NS \\
\hline - Level I* & 51.1 & 50.7 & 51.5 & \\
\hline - Level II** & 48.9 & 49.3 & 48.5 & \\
\hline $\begin{array}{l}\text { Previous research training during } \\
\text { undergraduate stage }\end{array}$ & & & & NS \\
\hline - No & 93.2 & 90.4 & 95.1 & \\
\hline - Yes & 6.8 & 9.6 & 4.9 & \\
\hline $\begin{array}{l}\text { Previous research training during } \\
\text { postgraduate stage }\end{array}$ & & & & $<0.001$ \\
\hline - No & 36.9 & 16.5 & 51.5 & \\
\hline - Yes & 63.1 & 83.6 & 48.5 & \\
\hline Previous research involvement & & & & 0.02 \\
\hline- No & 40.3 & 30.1 & 47.6 & \\
\hline - Yes & 59.7 & 69.9 & 52.4 & \\
\hline Previous research publication (s) & & & & 0.05 \\
\hline- No & 51.1 & 42.5 & 57.3 & \\
\hline - Yes & 48.9 & 57.5 & 42.7 & \\
\hline Previous research presentation (s) & & & & 0.05 \\
\hline - No & 48.3 & 39.7 & 54.4 & \\
\hline - Yes & 51.7 & 60.3 & 45.6 & \\
\hline
\end{tabular}

* Level I: Fellows, Instructors and Lecturers

**Level II: Senior Instructors and Assistant Professors

NS: Not significant

physicians working in different academic settings (both private and public sector universities). This study is also the first attempt to highlight differences in attitudes and barriers towards research in physicians active in research versus those who are not.

Overall, majority of physicians sampled, were not involved in research. However, the number of physicians currently involved in research was surprisingly comparable, if not better, to similar studies $[7,9,17]$ conducted in more developed parts of the world.

As expected, the number of male physicians working at a postgraduate level was higher in our institutes compared to females. Among the female faculty, involvement in research was significantly lower compared to males. This 
Table 2: Percentage distribution and factors associated with attitude and barriers towards research among junior faculty members of teaching hospitals in Pakistan

\begin{tabular}{|c|c|c|c|c|}
\hline Statements agreed & $\begin{array}{l}\text { Percent presently involved in } \\
\text { research }\end{array}$ & $\begin{array}{l}\text { Percent presently not } \\
\text { involved in research }\end{array}$ & $\begin{array}{l}\text { Odds Ratio } \\
\text { (95\% Cl) }\end{array}$ & $\begin{array}{c}\text { Adjusted Odds Ratio } \\
(95 \% \mathrm{Cl})\end{array}$ \\
\hline \multicolumn{5}{|c|}{ Attitude towards research } \\
\hline Research is helpful & $\mathrm{n}=69$ & $\mathrm{n}=8 \mathrm{l}$ & & \\
\hline - Promotes critical thinking & 72.6 & 43.7 & $\begin{array}{c}3.42 \\
(1.79-6.51)\end{array}$ & $\begin{array}{c}2.48 \\
(1.22-5.05)\end{array}$ \\
\hline - Improves patients' care & 67.1 & 39.8 & $\begin{array}{c}3.09 \\
(1.65-5.78)\end{array}$ & $\begin{array}{c}2.11 \\
(1.05-4.25)\end{array}$ \\
\hline - Helps in promotion & 61.6 & 44.7 & $\begin{array}{c}1.99 \\
(1.08-3.67)\end{array}$ & \\
\hline $\begin{array}{l}\text { - Helps professional } \\
\text { enhancement }\end{array}$ & 68.5 & 54.4 & $\begin{array}{c}1.83 \\
(0.97-3.4 \mid)\end{array}$ & \\
\hline $\begin{array}{l}\text { - Helps to changes health } \\
\text { policy }\end{array}$ & 50.7 & 48.5 & $\begin{array}{c}1.03 \\
(0.49-2.14)\end{array}$ & \\
\hline
\end{tabular}

\begin{tabular}{|c|c|c|c|c|}
\hline \multicolumn{5}{|c|}{ Barriers towards research } \\
\hline Research is difficult & $n=55$ & $\mathrm{n}=92$ & & \\
\hline $\begin{array}{l}\text { - Lack of research allotted } \\
\text { time }\end{array}$ & 64.4 & 68.0 & $\begin{array}{c}1.17 \\
(0.62-2.21)\end{array}$ & \\
\hline - Lack for research training & 52.1 & 68.0 & $\begin{array}{c}1.95 \\
(1.05-3.63)\end{array}$ & $\begin{array}{c}1.95 \\
(1.05-3.63)\end{array}$ \\
\hline - Lack of statistical support & 47.2 & 51.5 & $\begin{array}{c}0.33 \\
(0.34-1.17)\end{array}$ & \\
\hline - Lack of mentorship & 42.5 & 48.5 & $\begin{array}{c}1.29 \\
(0.69-2.34)\end{array}$ & \\
\hline - Lack of financial incentives & 28.8 & 33.0 & $\begin{array}{c}1.22 \\
(0.64-2.33)\end{array}$ & \\
\hline
\end{tabular}

finding is similar to some studies done in the US [6,7], one of which [6] cites low self-ability as a major barrier toward involvement in research. No distinct reason was identified in our study to explain this occurrence. However, this difference may be due to different cultural and social expectations and responsibilities faced by females in our setting in contrast to males: like household and marital responsibilities.

Historically staff training, infrastructure, and resources are considered stronger in the private as compared to public or government run hospitals in Pakistan. Thus it was a surprising finding in our study that a higher number of physicians from the public sector were currently involved in research compared doctors in to private universities. This may be explained by a recent influx of funds and support provided to our public sector universities through large grants by Higher Education Commission of Pakistan. The quality of research being done in both the public and private sectors however was not assessed in this study.

Another important finding of this study was an almost lack of undergraduate training in research provided to our medical students. A similar study from India reported that $91 \%$ of interns had no research experience in medical schools [18]. Exposing medical trainees at an earlier stage in their careers to the basics of medical research not only improves knowledge and attitudes toward research but also helps to improve their skills in searching and critically appraising medical literature, independent learning 
and writing $[19,20]$. This training may translate into an increased interest in research at a post-graduate level and generation of research not only as mandatory projects but also as an additional if not exclusive arm of their careers. Most of the research training of our participants was obtained at a postgraduate level, which in turn was one of the most important factors associated with current involvement in research. Physicians with prior research experience, publications and presentations were more likely to have ongoing research projects. This may be explained by an increased experience and know how in performing literatures searches, data collection, analyses and interpretation. Appropriate rewards like promotions and publications have also been found to be strong motivators and predictors for researcher productivity $[10,14,15]$. This may very well explain the greater involvement in active research of such participants, also a significant finding of this study.

This study was also able to identify differences in attitudes toward research among study participants very clearly. There were statistically significant differences between faculty actively involved in research, who had a more positive outlook towards research both at a patient care and personal professional level as compared to faculty not involved in ongoing projects.

Another main objective of our study was assessment of barriers of which, a lack of research training was only barrier to have statistically significant difference between those involved in research versus not. This barrier was also cited in another study done earlier in Pakistan [21]. Allocation of time is identified as one of the characteristics of research productivity among faculty at US medical schools [15]. Majority of study participants also pointed out lack of time as one of the barriers for not doing research. This barrier is also reported by other researchers as well $[7,9,12]$. Even though no statistically significant differences were found between the two groups of physicians involved and not involved in research, other barriers selected by both groups were considerable in number and fairly similar. Of note was that lack of financial incentives was the least selected by both groups.

One limitation of this study was that we did not look at the type of research done by the study participants. Even though not a study objective, information of the quantity and quality of research would have given more information of research output and reflected on adequacy of research. Secondly, a larger sample size would have allowed for a stronger analysis than the one performed in this study. Statistical validation of the data collection tool was done, nevertheless its face and content validity was well conducted. Despite these limitations, this study was able to capture a wider sample across four academic insti- tutions allowing for a better representation than in previous local studies.

\section{Conclusion}

Majority of the junior faculty of Pakistani medical universities who participated in this study were currently not involved in research and a very small proportion of them received any training during their undergraduate studies. The most significant factor associated with involvement in current research was research training during post-graduation education. It is encouraging to note that in this study a large majority of doctors considered research helpful for their profession and had positive attitudes towards research. However, at the same time, the preponderance of participating faculty considered it difficult to conduct research, with the most common barriers being lack of time, research training, statistical support and mentorship.

Thus, we recommend addressing the gaps and barriers identified by study participants with effective interventions. Gender differences in research involvement also needs attention. Teaching and training in research should be made compulsory during undergraduate as well as post-graduate studies. Giving some protected research time and participation in research methodology workshops and courses should be made readily available for faculty, with provision of statistical assistance. In addition, availability and support of supervisors and mentors should be assured. This work also paves way for further such studies at a larger scale that look at the quality of research training and output resulting from it.

\section{Competing interests}

The authors declare that they have no competing interests.

\section{Authors' contributions}

SS conceived and designed the study and prepared the manuscript. SK drafted and administered the questionnaires and managed the data. AKK analyzed and interpreted the data and provided intellectual feedback and supervision throughout the study. All authors read and approved the final manuscript.

\section{Acknowledgements}

We are grateful to all the faculty members for their participation in this study. We are thankful to Dr. Saima Akhund (Senior Instructor Research, department of Family Medicine, Aga Khan University) for her expert review and comments. We would also like to acknowledge Mr. Iqbal Azam (Assistant Professor of Biostatistics, department of Community Health Sciences, Aga Khan University) for his statistical support and feedback.

\section{References}

I. Lavis JN, Oxman AD, Moynihan R, Paulsen EJ: Evidence-informed health policy I-Synthesis of findings from a multi-method study of organizations that support the use of research evidence. Implement Sci 2008, 3:53. 
2. Fairhurst K, Huby G: From trial data to practical knowledge: qualitative study of how general practitioners have accessed and used evidence about statin drugs in their management of hypercholesterolemia. $B M]$ | 998, 3 I 7: | | 30-34.

3. Sadana R, D'Souza C, Hyder AA, Chowdhury AM: Importance of health research in South Asia. BMJ 2004, 328:826-30.

4. Hennink M, Stephenson R: Using research to inform health policy: barriers and strategies in developing countries. J Health Commun 2005, 10:163-80.

5. Rehan N: Medical research in Pakistan. J Coll Physicians Surg Pak 2003, I3:617.

6. Bakken LL, Sheridan J, Carnes M: Gender differences among physician-scientists in self-assessed abilities to perform clinical research. Acad Med 2003, 78: I 28I-86.

7. Lloyd T, Phillips BR, Aber RC: Factors that influence doctors participation in clinical research. Med Edu 2004, 38:848-5I.

8. Rosemann T, Szecsenyi J: General practitioners' attitudes towards research in primary care: qualitative results of a cross sectional study. BMC: Family Pract 2004, 5:31.

9. Jowett SM, Macleod J, Wilson S, Hobbs FD: Research in primary care: extent of involvement and perceived determinants among practitioners form one English region. $\mathrm{Br}$ J Gen Prac 2000, 50:387-89.

10. Shewan LG, Glatz JA, Bennett C, Coats AJ: Contemporary (postwills) survey of the views of Australian medical researchers: importance of funding, infrastructure and motivators for a research career. Med J Aust 2005, 183:606-II.

II. Askew DA, Clavarino AN, Glasziou PP, Del Mar CB: General practice research: attitudes and involvement of Queensland general practitioners. Med J Aust 2002, 177:74-7.

12. Gill S, Levin A, Djurdjev O, Yoshida E: Obstacles to residents' conducting research and predictors of publication. Acad Med 200I, 76:477.

13. Levine RB, Herbert RS, Wright SM: Resident research and scholarly activity in internal medicine residency training programs. J Gen Intern Med 2005, 20: I 55-9.

14. Bland C], Ruffin MT: Characteristics of a productive research involvement: literature review. Acad Med 1992, 67:385-97.

15. Brocato JJ, Mavis B: The research productivity of faculty in family medicine departments at U.S. medical schools: a national study. Acad Med 2005, 80:244-52.

16. Farooq S: Needed a research agenda. J Ayub Med Coll Abbottabad 2003, I 5: I-2.

17. Dakik HA, Kaidbey H, Sabra R: Research productivity of the medical faculty at the American University of Beirut. Postgrad Med J 2006, 82:462-4.

18. Chaturvedi S, Aggarwal OP: Training interns in populationbased research: Learners' feedback from I3 consecutive batches from a medical school in India. Med Educ 200I, 35:585-89.

19. Aslam F, Shakir M, Qayyum MA: Why the medical students are crucial to the future of research in South Asia. PLoS Med 2005, 2:e322.

20. Khan H, Khawaja MR, Waheed A, Rauf MA, Fatmi Z: Knowledge and attitudes about health research amongst a group of Pakistani medical students. BMC: Med Edu 2006, 6:54.

21. Aslam F, Qayyum MA, Muhmud H, Qasim R, Haque IU: Attitude and practices of postgraduate medical trainees towards research - a snapshot from Faisalabad. J Pak Med Assoc 2004 54:534-6.

\section{Pre-publication history}

The pre-publication history for this paper can be accessed here:

http://www.biomedcentral.com/1472-6920/9/68/prepub
Publish with Bio Med Central and every scientist can read your work free of charge

"BioMed Central will be the most significant development for disseminating the results of biomedical research in our lifetime. "

Sir Paul Nurse, Cancer Research UK

Your research papers will be:

- available free of charge to the entire biomedical community

- peer reviewed and published immediately upon acceptance

- cited in PubMed and archived on PubMed Central

- yours - you keep the copyright

Submit your manuscript here:

http://www.biomedcentral.com/info/publishing_adv.asp
BioMedcentral 